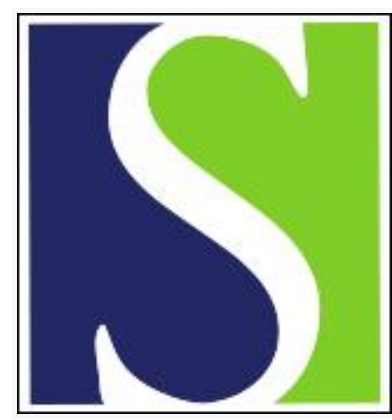

Scand J Work Environ Health 2014;40(5):502-510

https://doi.org/10.5271/sjweh.3438

Published online: 03 Jun 2014, Issue date: 01 Sep 2014

A retrospective cohort study of shift work and risk of incident cancer among German male chemical workers

by Yong M, Blettner M, Emrich K, Nasterlack M, Oberlinner C, Hammer GP

This industry-based retrospective cohort study showed an increased risk neither for cancer of all sites nor site-specific cancers in relation to the shift work under study. Explicit characterization of shift schedules merits more consideration with respect to circadian disruption in future studies.

Affiliation: BASF SE, GUA / CS - H306, Ludwigshafen, Germany. mei.yong@basf.com

Refers to the following texts of the Journal: 2007;33(5):336-343 2008;34(1):5-22 2009;35(4):309-318 2010;36(2):134-141 2013;39(2):170-177

The following articles refer to this text: $2015 ; 41(3): 259-267$; 2017;43(6):560-568; 2018;44(3):258-264

Key terms: cancer; cancer risk; chemical industry; chemical worker; circadian disruption; Germany; health surveillance; incidence; industry-based; male; retrospective cohort study; shift work

This article in PubMed: www.ncbi.nlm.nih.gov/pubmed/24892305

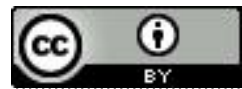




\title{
A retrospective cohort study of shift work and risk of incident cancer among German male chemical workers
}

\author{
by Mei Yong, PhD, ${ }^{1}$ Maria Blettner, PhD, ${ }^{2}$ Katharina Emrich, PhD, ${ }^{3}$ Michael Nasterlack, MD, ${ }^{1}$ Christoph \\ Oberlinner, MD, ${ }^{1}$ Gaël P Hammer, PhD ${ }^{2,4}$
}

\begin{abstract}
Yong M, Blettner M, Emrich K, Nasterlack M, Oberlinner C, Hammer GP. A retrospective cohort study of shift work and risk of incident cancer among German male chemical workers. Scand J Work Environ Health. 2014;40(5):502510. doi:10.5271/sjweh.3438
\end{abstract}

Objective Human evidence of carcinogenicity concerning shift work is inconsistent. This industry-based cohort study aimed to examine the relationship between working in a rotating shift and cancer incidence.

Methods The cohort consisted of male production workers (12 609 shift and 15219 day), employed in a large chemical industry for at least one year between 1995-2005, and residing in the German federal state of Rhineland-Palatinate. Incident cancer cases from 2000-2009 were identified through record linkage with the cancer registry of Rhineland-Palatinate. Information on exposure to shift work and potential confounders, including age, smoking status, job level, and employment duration, was extracted from the personnel and health records. Cox proportional hazard models were used to estimate hazard ratios (HR) with $95 \%$ confidence interval $(95 \%$ CI) adjusted for potential confounders.

Results Between 2000-2009, 518 and 555 cancer cases (excluding non-melanoma skin cancer) occurred among shift and day work employees, respectively. Compared to "never shift work", shift workers experienced an increased risk of cancers neither at all-sites (HR 1.04, 95\% CI 0.89-1.21) nor for prostate cancer in particular (HR $0.93,95 \%$ CI $0.71-1.21$ ). The risks of leukemia and esophagus cancer were increased if smoking was not taken into account, albeit based on small numbers. However, adjusting for smoking changed the HR and the risk diminished.

Conclusions Our analyses do not provide evidence for a carcinogenic effect of the shift system under study.

Key terms cancer risk; chemical industry; circadian disruption; Germany; health surveillance; incidence; industry-based.

By interfering both with biological and social circadian rhythms, shift work involving work at night poses several challenges to those who perform it. The resulting misalignment may be associated with generally increased health risks. Shift work involving exposure to light at night and the subsequent depression of endogenous melatonin was hypothesized to be an etiologic mechanistic pathway for developing breast cancer $(1,2)$. More generally, chronotype, sleep pattern, and circadian genes are supposed to act in the adaptation to shift work, and subsequently have influence on the direct or indirect pathways from shift work to the potential adverse health outcomes (3).
In 2007, the International Agency for the Research on Cancer (IARC) classified "shift work that involves circadian disruption" as probably carcinogenic (2A), based on sufficient evidence in experimental animals but limited evidence from epidemiological studies (4, 5). Since then, a body of literature has emerged from research on shift work and its impact on cancer risk for all sites $(6,7)$ and several site-specific cancers, such as prostate $(6,8)$, ovaries $(9,10)$, skin $(11)$, non-Hodgkin lymphoma (12), pancreas (13), and lung (14) in addition to breast cancer (15-21). However, evidence from epidemiological studies still remains inconsistent. In

1 Occupational Medicine and Health Protection, BASF SE, Ludwigshafen, Germany.

2 Institute for Medical Biostatistics, Epidemiology, and Informatics, University Medical Center, Johannes Gutenberg University Mainz, Mainz, Germany.

3 Cancer Registry of Rhineland-Palatine, Institute for Medical Biostatistics, Epidemiology and Informatics, University Medical Center, Johannes Gutenberg University Mainz, Mainz, Germany.

4 Registre Morphologique des Tumeurs, Laboratoire National de Santé, Luxembourg.

Correspondence to: Mei Yong, BASF SE, GUA / CS - H306, Ludwigshafen, Germany. [E-mail: mei.yong@basf.com] 
recent reviews, findings for an adverse association between night work and breast cancer were considered to be suggestive but not conclusive, while limited and inconsistent for cancers at other sites and all cancers combined $(22,23,24)$.

We have previously studied acute injury, chronic illness, and total mortality in two cohorts of male wage employees, respectively engaged in rotating shift and day work, followed up from 1996-2006 $(25,26)$, and all-cause and cancer-specific mortality (27) and mortality due to ischemic heart disease (28), followed up from 2000-2009. Here we found no difference between ever and never shift workers, nor dose-response relations with duration of shift work. The present study aims to further investigate total and site-specific cancer incidence risks, in this large industry-based cohort with largely homogeneous occupational profiles.

\section{Methods}

\section{Study design and population}

This study was designed as a retrospective cohort study of male production workers in a German chemical company. The cohort was defined in a previous study that was described in a former publication (25). Briefly, the initial shift cohort consisted of 14037 male wage employees who completed $\geq 1$ year of rotating shift work between 1995-2005. A cohort of 17095 day workers was identified as the referent population using the same search strategy in the work histories but excluding all employees who ever performed shift work or whose job titles were indicative of office work. Most of the initial cohorts were residents of Rhineland-Palatinate in Germany, 12609 (90\%) shift and 15219 (89\%) day workers. The present study that aims to compare the cancer incidence risks between the two sub-cohorts is based on this population. Incident cancer cases were identified through anonymous record linkage with the cancer registry of RhinelandPalatinate. The algorithm uses pseudonyms of the personal information including names, sex, date of birth, and place of residence to match cases. Cancer incidence was recorded for the period from 2000-2009. The later onset of the follow-up period compared to our earlier studies was due to the fact that an acceptable completeness of the cancer registry data was only achieved since the year 2000, owing to obligatory notification in the State of Rhineland-Palatinate.

\section{Cancer registry data}

This study is based on cancer cases registered in the Rhineland-Palatinate cancer registry that covers a popu- lation of 4 million with about 18000 cancer cases added each year. Since 1 January 2000, all RhinelandPalatinate physicians and dentists are legally obliged to report incident cancer cases to the cancer registry. This includes all malignant tumors, benign brain and central nervous system (CNS) tumors, brain and CNS tumors of uncertain behavior, malignant bladder tumors, carcinoma in situ, and tumors of uncertain behavior of the bladder. Since the beginning of 2000, the completeness of all incident cancer cases has been improving from $62.8 \%$ to the current $93 \%$. The case-finding in the cancer registry of the present study was successful. The diagnoses were classified according to the $10^{\text {th }}$ revision of the International Statistical Classification of Diseases and Related Health Problems (ICD-10). Results for cancer categories with $\geq 20$ cases are reported in the present paper.

\section{Shift schedules}

The shift cohort members work in either of two forms of fast forward-rotating 12-hour shift schedules approved for BASF's Ludwigshafen site, referred to as the $3 \times 12$ or $4 \times 12$ system because of the number of shift teams needed to run the schedules. In the $3 \times 12$ system with a sequence of shifts (day-night-off), a 12-hour day shift (06:00-18:00 hours) is followed 24 hours later by a 12-hour night shift (18:00-06:00 hours). After a day off, the employee returns to the day shift. With this shift schedule, there are 39 holidays and an additional 57 elective shifts off per year. The $4 \times 12$ schedule with a sequence of shifts (day-night-off-off) follows the same pattern except that there are two days off between the night shift and the next day shift. To compensate, there are only 33 holidays and 4 elective shifts off per year. Both shift schedules have the same rotating speed and the same working time, which sums up to 1709 hours per year. In fact, approximately 80 night shifts per year are worked by either group. The shift schedules differ only by a resting period of one or two days after the night shift. The number of sequential night shifts is never $>1$ in both systems. Possible differences between these two shift schedules are not the subject of the present study. Nevertheless, a previous evaluation did not suggest a difference between these two shift systems regarding their impact on subjective health status measured by the Work Ability Index (29).

\section{Validation of exposure measures}

Exposure status to shift work was defined dichotomously at entry into the study. Since job histories were not digitally recorded before 1995, information on working time history before this time point was therefore not routinely available. To assess the magnitude of the potential clas- 
sification error of shift assignment and to quantify the exposure duration, a validation study was performed in a representative sample of 300 cohort members. The shift and day cohorts were firstly stratified at quartiles of the job duration. Within each stratum, a "simple random sampling" technique was used, from which respective samples of 50 and 25 of the shift and day cohort were drawn. The complete job history of the sample was reconstructed based on archived health documents or injury records before 1995, in which shift work status was possibly documented. After 1995, all job records were retrieved from an internal personnel database. Two staff members in the medical department independently reviewed all documents, blinded to the initially defined shift status. If a working time schedule was noted in any document, the date of its issue was taken as evidence for working or not working shifts at this point in time. In case of discrepancies, a third person checked the entries and a consensus was reached. After the complete revision, the initially defined exposure status was unmasked and compared with the records before and after 1995 according to the data source. We found that $15 \%$ of the shift-work employees had transferred at least once to day work while $8 \%$ of the day workers transferred at least once to day work before 1995. After 1995, the figures were $14 \%$ and $3 \%$, respectively. Of note, those who have transferred twice or four times returned to the initial working time schedule again.

The error rate of exposure duration before 1995 was estimated quantitatively. Because the dates of the documents did not necessarily represent the true date of transfer that could have occurred between the dates of two successive documents, three scenarios were assumed for sensitivity analysis. In a best-case scenario, the shortest duration between two successive dates of discrepant records of working time status was assumed to be possibly misclassified, while in a worst-case scenario it was the longest duration. A mixed-case scenario, was somewhere in between the two extremes. As a result, among day workers, the misclassified exposure duration in shift work were $1.2 \%, 3.1 \%$, and $2.2 \%$, accordingly in best-, worst-, and mixed-case scenarios, and $9.8 \%, 13.4 \%$, and $11.6 \%$ in day work among shift workers.

\section{Confounders}

Smoking status, job level, and job duration were considered to be potential confounding factors. Smoking status at the entry into the study was used to define current, past, and non-smokers, and unknown. According to job level, cohort members were classified into manual labor or skilled/supervisory. Information on job duration in the company was retrieved from the personnel data and used as a surrogate measure of total exposure duration on the job.

\section{Statistical analysis}

To account for shift work in relationship with incident cancer risks, we used Cox proportional hazards models in our primary analysis to examine the impact of (i) shift versus day work, (ii) age at entry to follow-up, (iii) job level, (iv) smoking status, and (v) job duration. Job duration is considered as a proxy measure of exposure duration in shift work, at the same time adjusting for "total time worked in this chemical factory". Results are presented as hazard ratio (HR) with $95 \%$ confidence interval $(95 \% \mathrm{CI})$.

In our secondary analysis, an external comparison of site-specific standardized incidence ratios (SIR) was done separately for shift and day work employees. SIR were computed using age-, sex-, and calendar-yearspecific cancer incidence for the reference population of Rhineland-Palatinate. The expected numbers of cancer (E) for the time period 2000-2009 were compared with the observed numbers $(\mathrm{O})$, calculating SIR as the ratio between the observed and the expected numbers, and 95\% CI were computed based on Poisson distribution assumption. The SIR were calculated separately for the shift- and day cohorts. While we performed predominantly an internal comparison, a ratio of $\operatorname{SIR}\left(\mathrm{SIR}_{R}\right)$ of both cohorts with $95 \%$ CI was computed (30).

Since the incidence rates from a general population may not act as a proper reference, we emphasize the results from our internal analysis. As this is an explorative study, we have chosen not to employ the term "statistically significant" but rather to discuss differences that cannot be explained by random variation only.

A latency time of 20 years was defined prior to the analysis to estimate a potential latency period of cancer. The analyses were performed with SAS version 9.2 (SAS Institute, Cary, NC, USA).

\section{Results}

\section{Study population}

Baseline characteristics of rotating shift and day work employees in this male production population are presented in table 1 . The median age at entry to followup was well comparable between the cohorts [39.5 (interquartile range (IQR) 33.5-49.5) and 40.5 (IQR 32.5-50.5) years of age for shift and day workers, respectively.] Rotating shift employees were more likely to be assigned to jobs involving manual labor than day workers. Cigarette smoking was more prevalent among shift than day workers. Mean job duration was very similar between the cohorts: 25.0 and 25.1 years for shift and day workers, respectively. 
Table 1. Description of characteristics of rotating shift and day work cohort members residing in Rhineland-Palatinate. [IQR= interquartile range; $N A=$ not available]

\begin{tabular}{|c|c|c|c|c|c|c|c|c|}
\hline & \multicolumn{4}{|c|}{ Rotating shift ( $\mathrm{N}=12$ 609) } & \multicolumn{4}{|c|}{ Day work (N=15 219) } \\
\hline & $\mathrm{N}$ & $\% \quad 1$ & Median & $I Q R$ & $\mathrm{~N}$ & $\%$ & Median & IQR \\
\hline $\begin{array}{l}\text { Age at entry } \\
\text { to follow-up } \\
\text { (years) }\end{array}$ & & & 39.5 & $33.5-49.5$ & & & 40.5 & $32.5-50.5$ \\
\hline $\begin{array}{l}\text { Age at end } \\
\text { of follow-up } \\
\text { (years) }\end{array}$ & & & 49.5 & $43.5-59.5$ & & & 50.5 & $42.5-59.5$ \\
\hline \multicolumn{9}{|l|}{ Job level a } \\
\hline Manual 1 & 10786 & 85.5 & & & 7367 & 48.4 & & \\
\hline $\begin{array}{l}\text { Skilled/ } \\
\text { supervisory }\end{array}$ & 1823 & 14.5 & & & 7852 & 51.6 & & \\
\hline \multicolumn{9}{|l|}{$\begin{array}{l}\text { Cigarette } \\
\text { smoking }\end{array}$} \\
\hline Current & 5350 & 42.4 & & & 4145 & 27.2 & & \\
\hline Former & 4561 & 36.2 & & & 4246 & 27.9 & & \\
\hline Never & 2643 & 21.0 & & & 5122 & 33.7 & & \\
\hline NA & 55 & 0.4 & & & 1706 & 11.2 & & \\
\hline \multicolumn{9}{|l|}{$\begin{array}{l}\text { Employment } \\
\text { duration in } \\
\text { years }\end{array}$} \\
\hline $0-4$ & 77 & 0.6 & & & 55 & 0.4 & & \\
\hline $5-9$ & 427 & 3.4 & & & 459 & 3.0 & & \\
\hline $10-14$ & 1521 & 12.1 & & & 1048 & 6.9 & & \\
\hline $15-19$ & 2546 & 20.2 & & & 1677 & 11.0 & & \\
\hline $20-24$ & 2943 & 23.3 & & & 2730 & 17.9 & & \\
\hline $25-29$ & 2217 & 17.6 & & & 2125 & 14.0 & & \\
\hline $30-34$ & 1617 & 12.8 & & & 2402 & 15.8 & & \\
\hline $35-39$ & 797 & 6.3 & & & 2065 & 13.6 & & \\
\hline $40-44$ & 364 & 2.9 & & & 1817 & 11.9 & & \\
\hline$\geq 45$ & 100 & 0.8 & & & 841 & 5.6 & & \\
\hline
\end{tabular}

a Job level at entry into the study (>2000).

Internal comparison: all sites and site-specific cancer risk

During ten years of follow-up, $518(4.1 \%)$ and 555 (3.6\%) incident cancer cases (excluding non-melanoma skin cancer) occurred among rotating shift and day work employees, respectively.

Table 2 shows the HR of shift work in association with all sites except for non-melanoma skin cancer and site-specific cancer incidence, adjusted for age and job level. No difference of incidence of cancer at all sites was found (HR 1.02, 95\% CI 0.89-1.18). Compared to day workers, increased incidence of esophagus cancer, non-Hodgkin's lymphoma (NHL) and leukemia among shift workers was suggested, but no site showed a statistically significant association ( $\mathrm{P}>0.05)$.

After additional adjustment for smoking status, the HR decreased in total cancer and some smoking-related cancer sites, such as lip, oral cavity and pharynx, stomach, lung/bronchial system, bladder, and NHL, while the HR of leukemia increased and reached statistical significance. The HR of "total cancer" turned to below unity.

Results after further adjustment for employment duration increased most HR numerically. If a latency time of 20 years was considered, the results did not change (data not shown).

\section{External comparison: all sites and site-specific cancer risk}

Table 3 presents the SIR for cancer in shift and day work employees. The SIR of "cancer at all sites" were close to unity. The SIR of prostate cancer were increased both for shift (SIR 1.44, 95\% CI 1.22-1.70) and day (SIR 1.51, 95\% CI 1.30-1.74) workers, while the $\mathrm{SIR}_{\mathrm{R}}$ was below unity $\left(\operatorname{SIR}_{R} 0.95,95 \%\right.$ CI $\left.0.76-1.19\right)$. The SIR for lung cancer were decreased both in the shift and day cohorts $(0.70,95 \%$ CI $0.51-0.94$ and $0.48,95 \%$ CI $0.34-0.66$, respectively); however, the $\mathrm{SIR}_{\mathrm{R}}$ was slightly but nonsignificantly elevated $(1.46,95 \%$ CI $0.93-2.30)$. Bladder cancer incidence is increased for shift (SIR 1.61, 95\% CI 1.19-2.13) but not day (SIR 1.24, 95\% CI 0.91-1.65) workers. Again, $\mathrm{SIR}_{\mathrm{R}}$ is not significantly different from unity $(1.30,95 \%$ CI $0.85-1.99)$.

Comparing other cancer incidence risks between shift and day cohorts, some of the $\operatorname{SIR}_{\mathrm{R}}$ tend to be elevated, however, mostly due to respective deficits of cases in day workers.

\section{Discussion}

The present study aimed to assess the cancer incidence risks associated with shift work in a cohort of male production workers. During a 10-year follow-up, we did not find significant associations between shift work and either all sites or site-specific cancers after adjusting for age, smoking status, job level, and job duration. The risk of leukemia and esophagus cancer was suggested to be increased among the shift workers, albeit based on small numbers.

The present industry-based study is one of the very few studies investigating site-specific cancer incidence in a large cohort of shift workers, with an internal comparison with day workers. The findings from the internal comparison varied slightly depending on the models with respect to adjustment for explanatory factors beyond age and job level, including cigarette smoking and employment duration.

In the secondary analysis comparing with cancer risks in the general population, both day and shift work employees had increased SIR of prostate cancer and reduced risks of lung cancer. An increased SIR of bladder cancer was found among shift workers. With the exception of leukemia, none of the $\mathrm{SIR}_{R}$ between shift and day cohorts deviated statistically significantly from unity.

A substantial body of epidemiological studies addresses the carcinogenicity of shift work, mostly based on breast cancer, and predominantly among nurses. Few studies provided evidence for other cancer sites, particularly in male populations. Recent reviews 
Table 2. Hazard ratios (HR) of category-specific cancer incidence, comparing rotating shift to day workers. [95\% $\mathrm{Cl}=95 \%$ confidence interval]

\begin{tabular}{|c|c|c|c|c|c|c|}
\hline & \multicolumn{2}{|c|}{ Model 1 a } & \multicolumn{2}{|c|}{ Model 2 b } & \multicolumn{2}{|c|}{ Model $3^{c}$} \\
\hline & $\mathrm{HR}$ & $95 \% \mathrm{Cl}$ & $\mathrm{HR}$ & $95 \% \mathrm{Cl}$ & $\mathrm{HR}$ & $95 \% \mathrm{Cl}$ \\
\hline All sites (except for non-melanoma skin) cancer & 1.02 & $0.89-1.18$ & 0.98 & $0.85-1.13$ & 1.04 & $0.89-1.21$ \\
\hline Lip, oral cavity and pharynx (COO-C14) & 0.85 & $0.44-1.67$ & 0.73 & $0.37-1.47$ & 0.76 & $0.37-1.61$ \\
\hline Esophagus (C15) & 2.46 & $0.89-7.21$ & 1.91 & $0.70-5.55$ & 2.85 & $1.01-8.81$ \\
\hline Stomach (C16) & 1.30 & $0.60-2.83$ & 1.21 & $0.55-2.74$ & 1.15 & $0.49-2.72$ \\
\hline Colon and rectum (C18-C21) & 1.13 & $0.76-1.69$ & 1.24 & $0.81-1.88$ & 1.33 & $0.86-2.06$ \\
\hline Pancreas (C25) & 1.51 & $0.59-4.03$ & 1.38 & $0.53-3.79$ & 1.05 & $0.40-2.87$ \\
\hline Larynx (C32) & 1.42 & $0.43-4.66$ & 1.29 & $0.38-4.46$ & 1.31 & $0.36-4.84$ \\
\hline Lung/bronchial system (C33-C34) & 1.21 & $0.73-2.02$ & 0.92 & $0.55-1.54$ & 0.93 & $0.54-1.63$ \\
\hline Malignant melanoma (C43) & 0.51 & $0.26-0.95$ & 0.52 & $0.26-0.99$ & 0.53 & $0.26-1.04$ \\
\hline Prostate (C61) & 0.89 & $0.69-1.14$ & 0.85 & $0.66-1.09$ & 0.93 & $0.71-1.21$ \\
\hline Testis (C62) & 0.93 & $0.46-1.85$ & 0.91 & $0.44-1.84$ & 0.90 & $0.44-1.85$ \\
\hline Kidney, except renal pelvis (C64) & 1.21 & $0.59-2.46$ & 1.22 & $0.58-2.55$ & 1.21 & $0.56-2.62$ \\
\hline Urinary tract (C64-C66+C68) & 1.06 & $0.54-2.05$ & 1.12 & $0.56-2.23$ & 1.11 & $0.54-2.29$ \\
\hline Bladder (C67, D09.0, D41.4) & 1.05 & $0.66-1.68$ & 0.94 & $0.59-1.52$ & 1.01 & $0.61-1.68$ \\
\hline Non-Hodgkin's lymphoma (C82-C85) & 2.12 & $0.81-5.83$ & 1.81 & $0.69-5.00$ & 1.57 & $0.58-4.48$ \\
\hline Leukaemia (C91-C95) & 2.81 & $0.99-9.35$ & 3.15 & $1.06-11.19$ & 2.74 & $0.89-9.98$ \\
\hline Others & 0.99 & $0.97-1.03$ & 0.99 & 0.97-1.03 & 0.99 & $0.97-1.03$ \\
\hline
\end{tabular}

a Controlling for age and job level.

${ }^{\mathrm{b}}$ Controlling for age, job level, and cigarette smoking.

${ }^{c}$ Controlling for age, job level, cigarette smoking, and employment duration in categories.

found limited and inconsistent evidence for a risk of cancers at other sites and all sites combined $(22,23$, 24). Our present paper mainly discusses cancers at all sites combined, cancer at other sites, rather than prostate cancer; the latter will be reported and discussed in detail in another paper (Hammer et al in preparation).

By the time of the IARC assessment, one study among females and another study among males reported all sites and site-specific cancer incidences $(31,32)$. The results are in agreement with ours. After the IARC ruling, a large cohort study including all Nordic countries and 54 occupational categories found that all risks for occupations assumed to involve shift work assessed by means of the Finnish job exposure matrix (JEM) were also around unity. Several elevated site-specific cancer risks were reported in a case-control study in which a variety of statistical models including numerous confounders were used (7). The authors considered their findings to be contradictory and perplexing because of apparent excess risks at a number of tumor sites, but no hint of a duration-response relationship (7).

Our findings with respect to skin cancer are in agreement with another cohort study based on 10799 incident skin cancers from a cohort of 68336 female nurses that reported reduced risks for skin cancer and for melanoma (11).

The present study found increased SIR for shift workers, both for the bladder and urinary tract. In the internal comparison, the HR of both categories were close to unity. The HR for bladder cancer turned below unity after additional adjustment for smoking, while the HR for urinary tract did not. Our results are in accordance with that of another cohort study among males, which categorized urinary organs together, while the case-control study found significantly increased risks, comparing ever versus never shift work (7). Being in a chemical company, a potential exposure to carcinogenic substances in the past (eg, aromatic amines) may lead to increased risk of bladder cancer. On the other hand, preventive measures, such as a regular screening program that is offered to employees with past exposure to carcinogenic aromatic amines, may additionally introduce diagnostic bias (33). This may explain in part the increased SIR of bladder cancer in table 3 .

Bronchial and lung carcinoma has rarely, if ever, been linked to night work. This may be due to the fact that cigarette smoking is by far the most important cause for this type of cancer, and the generally less favorable smoking behavior of shift workers might mask any weak association with shift work, if existing. It is thus not surprising that in the internal comparison of our study population, the HR for bronchial and lung cancer turned to below unity after additional adjustment for smoking. Interestingly, the study by Schwartzbaum and co-workers (32) also found significantly reduced SIR of lung cancer for shift workers, while two other studies found increased risks for shift work $(7,14)$.

In our study, notably, an increased risk (not statistically significant) for NHL was suggested based on a total of 27 cases. In the external comparisons, the SIR for the shift workers was close to unity, while fewer cases than expected were observed among the day workers. Analogously, the SIR for leukemia of both the shift- and day workers were not significantly increased in reference to the general population, though coupled with more disparity between the groups. The HR based on 
Table 3. Standardized incidence ratios (SIR) of rotating shift and day workers compared with the incidence rates of male population of Rhineland-Palatinate. [Obs=observed number; Exp=expected number; SIR=age-standardized incidence ratio; $S I R_{R}=$ ratio of $S I R ; 95 \%$ $\mathrm{Cl}=$ confidence interval]

\begin{tabular}{|c|c|c|c|c|c|c|c|c|c|c|}
\hline & \multicolumn{4}{|c|}{ Shift } & \multicolumn{4}{|c|}{ Day } & \multicolumn{2}{|c|}{ Shift versus day } \\
\hline & Obs & Exp & SIR & $95 \% \mathrm{Cl}$ & Obs & Exp & SIR & $95 \% \mathrm{Cl}$ & $\mathrm{SIR}_{\mathrm{R}}$ & $95 \% \mathrm{Cl}$ \\
\hline All sites (except non-melanoma skin cancer) & 518 & 478.0 & 1.08 & $0.99-1.18$ & 555 & 589.6 & 0.94 & $0.86-1.02$ & 1.15 & $0.97-1.36$ \\
\hline Lip, oral cavity, and pharynx (C00-C14) & 23 & 24.9 & 0.92 & $0.59-1.39$ & 21 & 31.1 & 0.68 & $0.42-1.03$ & 1.35 & $0.72-2.60$ \\
\hline Esophagus (C15) & 14 & 10.9 & 1.28 & $0.70-2.15$ & 7 & 13.6 & 0.51 & $0.21-1.06$ & 2.51 & $0.94-7.31$ \\
\hline Stomach (C16) & 17 & 16.0 & 1.06 & $0.62-1.70$ & 16 & 19.7 & 0.81 & $0.46-1.32$ & 1.31 & $0.62-2.77$ \\
\hline Colon and rectum (C18-C21) & 69 & 64.0 & 1.08 & $0.84-1.36$ & 68 & 78.5 & 0.87 & $0.67-1.10$ & 1.24 & $0.88-1.77$ \\
\hline Pancreas (C25) & 12 & 12.3 & 0.98 & $0.50-1.71$ & 10 & 15.2 & 0.66 & $0.31-1.21$ & 1.48 & $0.59-3.83$ \\
\hline Larynx (C32) & 7 & 9.4 & 0.74 & $0.30-1.53$ & 7 & 11.8 & 0.59 & $0.24-1.22$ & 1.25 & $0.38-4.19$ \\
\hline Lung/bronchial system (C33-C34) & 46 & 65.5 & 0.70 & $0.51-0.94$ & 39 & 81.1 & 0.48 & $0.34-0.66$ & 1.46 & $0.93-2.30$ \\
\hline Malignant melanoma (C43) & 27 & 24.7 & 1.09 & $0.72-1.59$ & 40 & 30.2 & 1.33 & $0.95-1.81$ & 0.82 & $0.49-1.38$ \\
\hline Prostate (C61) & 146 & 101.3 & 1.44 & $1.22-1.70$ & 191 & 126.6 & 1.51 & $1.30-1.74$ & 0.95 & $0.76-1.19$ \\
\hline Testis (C62) & 16 & 15.6 & 1.02 & $0.58-1.66$ & 22 & 18.6 & 1.18 & $0.74-1.79$ & 0.86 & $0.43-1.73$ \\
\hline Kidney (except renal pelvis) (C64) & 24 & 18.9 & 1.27 & $0.81-1.89$ & 21 & 23.3 & 0.90 & $0.56-1.38$ & 1.41 & $0.75-2.66$ \\
\hline Urinary tract $(\mathrm{C} 64-\mathrm{C} 66+\mathrm{C} 68)$ & 26 & 20.8 & 1.25 & $0.81-1.83$ & 25 & 25.6 & 0.98 & $0.63-1.44$ & 1.28 & $0.71-2.31$ \\
\hline Bladder (C67, D09.0, D41.4) & 49 & 30.3 & 1.61 & $1.19-2.13$ & 46 & 37.1 & 1.24 & $0.91-1.65$ & 1.30 & $0.85-1.99$ \\
\hline Non-Hodgkin’s Lymphoma (C82-C85) & 15 & 13.9 & 1.08 & $0.60-1.78$ & 12 & 16.9 & 0.71 & $0.37-1.24$ & 1.52 & $0.66-3.56$ \\
\hline Leukaemia (C91-C95) & 16 & 10.6 & 1.51 & $0.87-2.46$ & 6 & 12.8 & 0.47 & 0.17-1.02 & 3.21 & $1.20-10.05$ \\
\hline Others & 19 & 27.9 & 0.68 & $0.41-1.06$ & 26 & 34.3 & 0.76 & $0.50-1.11$ & 0.89 & $0.47-1.69$ \\
\hline
\end{tabular}

the internal comparison varied between 2.74-3.15, and from marginal non-significance to significance, depending upon the model. This was on the one hand due to the limited number of cases and, on the other hand, lay in the fact that the SIR have methodological fallacy with respect to comparability between the study population and the reference population. Nevertheless, it is not possible to rule out residual confounding associated with shift status completely, either in the internal or external comparison. To date, only one study (12) addressed the risk of NHL in relationship to night work, assessed by means of the Finnish JEM. The etiology of leukemia and NHL is, however, not well understood. The observed increased risks might possibly be linked to the exposure to chemical substances, eg, benzene at the workplace and the exposure may not have been evenly distributed between the shift and day cohorts. In the present study, it was not possible to adjust for this potential confounder because, due to data protection concerns, information about workplace related exposures had to be dealt with anonymously. A real effect of shift work can therefore not be ruled out with confidence. Recently, the hypothesis was put forward that the clock gene (Per2), which determines the circadian expression, was linked to cancer and to NHL in particular (34). Another hypothesis is that shift work might modify the toxic mechanism of benzene during the night time. Based on the limited numbers of leukemia and NHL cases, a more in-depth investigation is desirable but not realistic at present.

Few existing studies have reported the risk of colorectal cancer. The present study does not suggest an increased colorectal cancer risk after either internal or external comparison. Our finding is in accordance with the studies among men and women $(32,35)$, with the exception that the case-control study found 2-fold increased risks both for colon and rectum cancer in "ever night" workers (7).

\section{Limitations and strengths}

The present study is a large retrospective cohort study with cancer diagnoses retrieved from a cancer registry, based on mandatory reporting by general practitioners, diagnosing institutions and the use of death certificates. The completeness of reported cancer cases was estimated to be about $80 \%$. Despite the on-going improvement of cancer registry completeness, incompleteness of cancer registration may introduce bias and loss of statistical power. A differential reporting of cancer cases to the registry based on shift status is however improbable. A similar percentage of shift and day workers live in Rhineland-Palatinate and elsewhere, so that the exclusion of workers residing in a neighboring state affected both groups evenly and was unlikely to have introduced bias but rather led to an additional loss of statistical power.

Possible misclassification of exposure status is a major concern in the present study and generally in shift work research. In the majority of literature on shift work, the exposure to shift work was measured via self-report or JEM. Validation studies have usually not been carried out. Information from JEM and survey about relevant exposures in shift work studies was considered to be rather crude (36). In the present study, information on exposure to shift work after since start of employment in the company was retrieved from the personnel data, which could be considered to be objective and therefore a strength of the present study. The complete job histo- 
ries, however, were not digitally recorded before 1995 and therefore not routinely available. For this reason, a random sample from the cohort was drawn to estimate the potential misclassification error of exposure assignment and to quantify the exposure duration. Briefly, $5 \%$ of the day workers (as defined in the study) have transferred at least once to shift work while $18 \%$ of the shift workers have transferred to day work. In a mixed-case scenario of sensitivity analysis, an error rate of exposure duration was calculated as $2.2 \%$ and $11.6 \%$, respectively, for the sub-cohorts of day and shift work. We therefore think that the resulting bias is limited. Information on potential exposure to shift work prior to this employment is unfortunately not available. The fact that the respective median age at start of employment in BASF was 17 and 23 years, respectively, among day and shift work cohorts (table 1) also suggests minor potential for bias.

In the present study, stochastic record linkage using encrypted identifiers was used for case-finding, since no national individual identification number is available. Most German cancer registries use this method to link notifications pertaining to the same person or cancer. Matching scores between pairs of data records are computed to judge if two notifications pertain to the same individual. Potential errors could be introduced by erroneously linking records from distinct individuals (homonym errors) and failure to link records on the same individuals (synonym errors) (37). Error rates for both types of errors were investigated in preparative work and found to be reasonably low. The matching scores of the cohort members that were matched to records from the cancer registry were categorized into good, moderate, and poor. All matches were reviewed by trained registry staff. Among a total of 1073 cancer cases, $1035(96 \%), 32(3 \%)$, and $6(1 \%)$ as well as among the subgroup of 337 prostate cancer cases, 322 $(95 \%), 12(4 \%)$, and $3(1 \%)$ were respectively classified into good, moderate, and poor. Hence, the potential for homonym or synonym errors is low.

A possible healthy worker effect is a major issue in epidemiological research of shift work. It may be induced through both initial and on-going selection based on health-related criteria into, or out of, shift or day work. However, the magnitude of a select-in effect is presumably not large, because later cancer risks are not easily predictable at the time of initial employment, and the mere presence of risk factors for cancer are usually not a criterion for the selection into or out of shift work. To correct a potential on-going selection due to differentially declining health status, the method to include a term for employment duration in regression models (38) was adopted in the present study. The issue of healthy worker effect in cancer mortality has been discussed thoroughly in our previous paper (27).

In reference to the general population, a serious underestimation of the cancer risk in a given working population is generally assumed. A large cohort of randomly selected Norwegian workers indicated an underestimation of overall cancer incidence (SIR 0.91, 95\% CI 0.89-0.93) among male workers but potential for both under- and overestimation for some sites of cancer (39). The direction of false estimation depends partly on the occupational exposure and the lifestyle factors that are potentially related with the occupation. All these factors cannot be adjusted for with respect to SIR. This fact underlines the advantage of an internal comparison within a comparatively homogeneous population, which represents a strength of the present study.

While comparability to the general population is probably limited, the present study focuses on the internal comparison between the day and shift work cohorts. To handle the issue of internal comparability, firstly we restricted the study population to production employees to achieve maximum comparability with respect to occupational risk profiles, socioeconomic status, and age distribution. Secondly, employment duration was adjusted for, assuming that employment duration is a proxy for work-related health risks (eg, handling of chemicals), which should mostly be comparable in both groups. Finally, information regarding both exposure and outcome was collected from personnel records and medical data. This differs substantially from other studies gathering information via questionnaires or JEM, and hence excludes recall bias as a potential source of error.

To summarize, this large retrospective cohort study did not show an increased risk of cancer at all sites or site-specific cancers in relation to shift work. The inconsistency across studies done to date raises again the question about the etiologic role of shift work in association with cancer. In particular, the impact of different shift schedules merits more consideration with respect to circadian disruption in future studies. The shift systems examined in our study are fast forward-rotating, with night work always followed by a resting period of 24 (old system) or 48 (new system) hours, respectively. Thus, the number of sequential night shifts is never more than one. These shift systems are not representative of all industries. Therefore, our results may not simply be extrapolated to other populations of shift workers and cannot serve to dismiss concerns about the health hazards of shift work in general.

\section{Acknowledgement}

We wish to thank the staff of the Cancer Registry of Rhineland-Palatine for their effort in data comparison and preparation, Mr Schuster, Mrs Zerna, and Mrs Wohlfahrt from the Department of Occupational Medi- 
cine and Health Protection of BASF for their efforts in reviewing the archives, and the Deutsche Gesetzliche Unfallversicherung (DGUV) for funding this study (grant no. 617.0 - FP-0332).

\section{References}

1. Schernhammer ES, Schulmeister K. Melatonin and cancer risk: does light at night compromise physiologic cancer protection by lowering serum melatonin levels? $\mathrm{Br} \mathrm{J}$ Cancer. 2004;90:9410-43. http://dx.doi.org/10.1038/sj.bjc.6601626.

2. Stevens RG. Light-at-night, circadian disruption and breast cancer: assessment of existing evidence. Int $\mathrm{J}$ Epidemiol. 2009;38:963-70. http://dx.doi.org/10.1093/ije/dyp178.

3. Gamble KL, Motsinger-Reif AA, Hida A, Borsetti HM, Servick SV, Ciarleglio CM, et al. Shift work in nurses: contribution of phenotypes and genotypes to adaptation. PLoS One. 2011;6(4):e18395. http://dx.doi.org/10.1371/journal. pone. 0018395 .

4. Straif K, Baan R, Grosse Y, Secretan B, El Ghissassi F, Bouvard V, et al. Carcinogenicity of shiftwork, painting, and fire-fighting. Lancet Oncol. 2007;8:1065-6. http://dx.doi. org/10.1016/S1470-2045(07)70373-X.

5. International Agency for Research on Cancer (IARC). Painting, Firefighting, and Shiftwork. Lyon: IARC; 2010. IARC Monographs on the Evaluation of Carcinogenic Risks to Humans, vol 98.

6. Pukkala E, Martinsen JI, Lynge E, Gunnarsdottir HK, Sparén P, Tryggvadottir L, et al. Occupation and cancer - follow-up of 15 million people in five Nordic countries. Acta Oncol. 2009;48:646-790. http://dx.doi. org/10.1080/02841860902913546.

7. Parent MÉ, El-Zein M, Rousseau MC, Pintos J, Siemiatycki J. Night work and the risk of cancer among men. Am J Epidemiol. 2012;176:751-9. http://dx.doi.org/10.1093/aje/ kws318.

8. Kubo T, Oyama I, Nakamura T, Kunimoto M, Kadowaki K, Otomo $\mathrm{H}$, et al. Industry-based retrospective cohort study of the risk of prostate cancer among rotating-shift workers. Int J Urol. 2011;18:206-11. http://dx.doi.org/10.1111/j.14422042.2010.02714.x.

9. Poole EM, Schernhammer ES, Tworoger SS. Rotating night shift work and risk of ovarian cancer. Cancer Epidemiol Biomarkers Prev. 2011;20:934-8. http://dx.doi. org/10.1158/1055-9965.EPI-11-0138.

10. Bhatti P, Cushing-Haugen KL, Wicklund KG, Doherty JA, Rossing MA. Nightshift work and risk of ovarian cancer. Occup Environ Med. 2013;70:231-7. http://dx.doi. org/10.1136/oemed-2012-101146.

11. Schernhammer ES, Razavi P, Li TY, Qureshi AA, Han J. Rotating night shifts and risk of skin cancer in the nurses' health study. J Natl Cancer Inst. 2011;103:602-6. http:// dx.doi.org/10.1093/jnci/djr044.
12. Lahti TA, Partonen T, Kyyrönen P, Kauppinen T, Pukkala E. Night-time work predisposes to non-Hodgkin lymphoma. Int J Cancer. 2008;123:2148-51. http://dx.doi.org/10.1002/ ijc. 23566 .

13. Lin Y, Ueda J, Yagyu K, Kurosawa M, Tamakoshi A, Kikuchi S. A prospective cohort study of shift work and the risk of death from pancreatic cancer in Japanese men. Cancer Causes Control. 2013;24:1357-61. http://dx.doi.org/10.1007/ s10552-013-0214-0.

14. Schernhammer ES, Feskanich D, Liang G, Han J. Rotating night-shift work and lung cancer risk among female nurses in the United States. Am J Epidemiol. 2013;178:1434-41. http:// dx.doi.org/10.1093/aje/kwt155.

15. Pronk A, Ji BT, Shu XO, Xue S, Yang G, Li HL, et al. Nightshift workand breast cancer risk in a cohort of Chinese women. Am J Epid. 2010;171(9):953-9. http://dx.doi.org/10.1093/ aje/kwq029.

16. Pesch B, Harth V, Rabstein S, Baisch C, Schiffermann M, Pallapies D, et al. Night work and breast cancer - results from the German GENICA study. Scand J Work Environ Health. 2010;36:134-41. http://dx.doi.org/10.5271/sjweh.2890.

17. Lie JA, Kjuus H, Zienolddiny S, Haugen A, Stevens RG, Kjærheim K. Night work and breast cancer risk among Norwegian nurses: assessment by different exposure metrics. Am J Epidemiol. 2011;173:1272-9. http://dx.doi. org/10.1093/aje/kwr014.

18. Hansen J, Lassen CF. Nested case-control study of night shift work and breast cancer risk among women in the Danish military. Occup Environ Med. 2012;69:551-6. http://dx.doi. org/10.1136/oemed-2011-100240.

19. Hansen J, Stevens RG. Case-control study of shift-work and breast cancer risk in Danish nurses: impact of shift systems. Eur J Cancer. 2012;48:1722-9. http://dx.doi.org/10.1016/j. ejca.2011.07.005.

20. Knutsson A, Alfredsson L, Karlsson B, Akerstedt T, Fransson EI, Westerholm $P$ et al. Breast cancer among shift workers: results of the WOLF longitudinal cohort study. Scand J Work Environ Health. 2013;39:170-7. http://dx.doi.org/10.5271/ sjweh.3323.

21. Menegaux F, Truong T, Anger A, Cordina-Duverger E, Lamkarkach F, Arveux P et al. Night work and breast cancer: a population-based case-control study in France (the CECILE study). Int J Cancer. 2013;132:924-31. http://dx.doi. org/10.1002/ijc.27669.

22. Kolstad HA. Nightshift work and risk of breast cancer and other cancers--a critical review of the epidemiologic evidence. Scand J Work Environ Health. 2008;34:5-22. http://dx.doi. org/10.5271/sjweh.1194.

23. Wang XS, Armstrong MEG, Cairns BJ, Key TJ, Travis RC. Shift work and chronic disease: the epidemiological evidence. Occup Med. 2011;61:78-89. http://dx.doi.org/10.1093/ occmed/kqr001.

24. Yong M, Nasterlack M. Shift work and cancer - state of science and practical consequences. Arh Hig Rada Toksikol. 2012;63:153-60. http://dx.doi.org/10.2478/10004-1254-632012-2209. 
25. Ott MG, Oberlinner C, Lang S, Hoffmann G, Nasterlack M, Pluto RP, et al. Health and safety protection for chemical industry employees in a rotating shift system: Program design and acute injury and illness experience at work. J Occup Environ Med. 2009;51:221-31. http://dx.doi.org/10.1097/ JOM.0b013e318192bd0f.

26. Oberlinner C, Ott MG, Nasterlack M, Yong M, Messerer P, Zober A, et al. Medical program for shift workers - impacts on chronic disease and mortality outcomes. Scand J Work Environ Health. 2009;35:309-18. http://dx.doi.org/10.5271/ sjweh.1332.

27. Yong M, Nasterlack M, Messerer P, Oberlinner C, Lang S. A retrospective cohort study of shift work and risk of cancer specific mortality in German male chemical workers. Int Arch Occup Environ Health. 2014;87:175-83. http://dx.doi. org/10.1007/s00420-013-0843-3.

28. Yong M, Nasterlack M, Germann C, Lang S, Oberlinner C. Shift work and risk of non-cancer mortality in a cohort of German male chemical workers. Int Arch Occup Environ Health. 2013 Dec 3 [Epub ahead of print]. http://dx.doi. org/10.1007/s00420-013-0922-5

29. Yong M, Nasterlack M, Pluto RP, Elmerich K, Karl D, Knauth P. Is health, measured by Work Ability Index, affected by 12hour rotating shift schedules? Chronobiol Int. 2010;27:113548. http://dx.doi.org/10.3109/07420528.2010.490111.

30. Newcombe RG, Altman DG. Proportions and their differences. In: Altman DG, Machin D, Bryant TN, Gardner MJ, editors. Statistics with confidence. 2nd edition. London: BMJ; 2000. p. $57-72$.

31. Tynes T, Hannevik M, Andersen A, Vistnes AI, Haldorsen T. Incidence of breast cancer in Norwegian female radio and telegraph operators. Cancer Causes Control. 1996;7:197-204. http://dx.doi.org/10.1007/BF00051295.
32. Schwartzbaum J, Ahlbom A, Feychting M. Cohort study of cancer risk among male and female shift workers. Scand J Work Environ Health. 2007;33:336-43. http://dx.doi. org/10.5271/sjweh.1150.

33. Pesch B, Taeger D, Johnen G, Gawrych K, Bonberg N, Schwentner C, et al. Screening for bladder cancer with urinary tumor markers in chemical workers with exposure to aromatic amines. Int Arch Occup Environ Health. 2013 Oct 16 [Epub ahead of print]. http://dx.doi.org/10.1007/s00420-013-09163.

34. Zhu Y, Leaderer D, Guss C, Brown HN, Zhang Y, Boyle P. Ala394Thr polymorphism in the clock gene NPAS2: a circadian modifier for the risk of non-Hodgkin's lymphoma. Int J Cancer 2007;120:432-5. http://dx.doi.org/10.1002/ ijc. 22321 .

35. Schernhammer ES, Laden F, Speizer FE, Willet WC, Hunter DJ, Kawachi I, et al. Night-shift work and risk of colorectal cancer in the Nurses' Health Study. J Natl Cancer Inst. 2003;95:825-8. http://dx.doi.org/10.1093/jnci/95.11.825.

36. Stevens RG, Hansen J, Costa G, Haus E, Kauppinen T, Aronson KJ, et al. Considerations of circadian impact for defining 'shift work' in cancer studies: IARC Working Group Report. Occup Environ Med. 2011;68:154-62. http://dx.doi. org/10.1136/oem.2009.053512.

37. Brenner H, Schmidtmann I. Effects of record linkage errors on disease registration. Meth Inform Med. 1998;37:69-74.

38. Park RM. The healthy worker survivor effect and mortality at two automotive engine manufacturing plants. Am J Ind Med.1996;30:655-63. http://dx.doi.org/10.1002/(SICI)10970274(199612)30:6<655::AID-AJIM2>3.0.CO;2-Q.

39. Kirkeleit J, Riise T, Bjørge T, Christiani DC. The healthy worker effect in cancer incidence studies. Am J Epidemiol. 2013;177:1218-24. http://dx.doi.org/10.1093/aje/kws373.

Received for publication: 7 January 2014 